\title{
A UTILIZAÇÃO DO SOFTWARE GEOGEBRA COMO FERRAMENTA PEDAGÓGICA NA CONSTRUÇÃO DE UMA UNIDADE DE ENSINO POTENCIALMENTE SIGNIFICATIVA (UEPS)
}

\author{
Tiago Nery Ribeiro \\ DFCI/ Universidade Federal de Sergipe \\ tnribeiro@globo.com \\ Divanízia do Nascimento Souza \\ DFI/ Universidade Federal de Sergipe \\ divanizi@ufs.br
}

\section{Resumo}

A inserção das tecnologias da informação e comunicação nas escolas é um processo que já foi iniciado, e que vem modificando o perfil do processo de ensino-aprendizagem. A partir disso, procurando inserir tais tecnologias em sala de aula, tivemos como objetivo analisar as respostas de alunos referentes a questionários aplicados durante o desenvolvimento e aplicação de uma Unidade de Ensino Potencialmente Significativa (UEPS), utilizando o software GeoGebra na aprendizagem do conteúdo triângulos retângulos congruentes. Neste trabalho utilizamos como aporte teórico a Teoria da Aprendizagem Significativa de Ausubel e como metodologia, de natureza qualitativa, tendo como instrumento a aplicação de um questionário aos sujeitos da pesquisa, que foram 16 alunos participantes do projeto de extensão intitulado "Nivelamento" do campus Professor Alberto Carvalho da Universidade Federal de Sergipe. Com base nos resultados das atividades realizadas e nas características de uma UEPS citadas por Moreira (2011), o software GeoGebra pode ser um material potencialmente significativo, pois demonstrou ser uma ferramenta que proporcionou melhor captação de significados, compreensão de conceitos, melhor capacidade de explicação, relacionou conceitos e aplicou o conhecimento adquirido para a solução de situações-problema.

Palavras-chave: Educação Matemática, Unidade de Ensino Potencialmente Significativa (UEPS), Aprendizagem Significativa, GeoGebra.

\begin{abstract}
The integration of information and communication technologies in schools is a process that has already started, and that has been changing the profile of the teaching-learning process. From there, trying to enter these technologies in the classroom, we had to analyze the responses of students regarding the questionnaires applied during the development and implementation of a Potentially Meaningful Teaching Units (PMTU) using the GeoGebra software learning content triangles congruent rectangles. In this work we used as theoretical support the Meaningful Learning Theory of Ausubel. In this methodology, a questionnaire was given to 16 students participating in the extension project entitled "Leveling" on campus professor Alberto Carvalho of the Federal University of Sergipe. Based on the results of the activities and in the PMTU characteristics cited by Moreira (2011) it could conclude that GeoGebra software can be a material Potentially Meaningful. this due to its ability to better capture meanings, understanding of concepts, best explanation capacity, related concepts and applied knowledge to the solution of problem situations.
\end{abstract}

Keywords: Mathematics Education, Potentially Meaningful Teaching Units (PMTU), Meaningful Learning, GeoGebra. 


\section{INTRODUÇÃO}

Com a evolução das Tecnologias da Informação e Comunicação (TIC) na sociedade, todos os níveis escolares são afetados por transformações que demandam a busca por recursos didáticos que estabeleçam novas relações cognitivas entre os indivíduos e que permite, segundo a Lei de Diretrizes e Bases (LDB, 1996), uma retirada da escola do processo de isolamento social, criando um novo significado social e cultural para todo o processo de ensino e aprendizagem, claramente expressos nos princípios e fins da própria lei.

A partir dessa demanda por estratégias de ensino que utilizem-se de recursos tecnológicos, métodos tradicionais de ensino podem tornar-se insuficientes para a aprendizagem de eventos científicos dinâmicos, difíceis de serem explicados através de recursos estáticos, como o quadro e giz; que possam ter o potencial de desestimular a criatividade e o envolvimento dos aprendizes em uma ação pedagógica reflexiva e transformadora.

Ao se utilizar as TIC como uma ferramenta dinâmica de ensino, as informações são interpretadas e utilizadas pelo aluno, interagindo com as interfaces da máquina, a partir das diversas possibilidades que se renovam e se modificam continuamente. Assim, o aluno participa do desenvolvimento de um processo centrado nas suas necessidades, proporcionando uma ação ativa e controlada das situações de aprendizagem

Com o software GeoGebra buscamos, através da geometria dinâmica, uma alternativa para dinamizar o processo de ensino-aprendizagem, tornando-o mais significativo para o aluno, por considerar que esse software possibilita interação a partir do controle das ações envolvidas no processo de estudo, que pode ser de forma lenta e gradual, em repetidas vezes. A partir da geometria dinâmica, esperamos lograr objetos tangíveis e variáveis que podem se tornar, segundo Laborde (2005), uma ferramenta nas mãos do professor na apresentação e visualização de objetos da matemática para os alunos.

Para Mason \& Heal:

[...] ser capaz de mover objetos na tela ao redor do espaço (e assim ao longo do tempo) pode aumentar significativamente para o usuário o sentido do conceito subjacente como um objeto e não apenas em si mesmo, mas um meio a algo invariável, mudança de propriedades geométricas são percebidos em um ambiente de geometria dinâmica como invariante na variação da 
figura, exatamente da mesma maneira como uma identidade algébrica. (MASON \& HEAL, 1995, p.301, apud LABORDE, p. 22).

Assim, a geometria dinâmica permite transformar objetos estáticos em objetos que podem ser manipulados através da tela do computador, imprimindo-se um movimento aos objetos através de suas construções. Segundo Souza e Gravina,

[...] o "desenho em movimento" torna-se revelador dos invariantes que são decorrências implícitas da construção feita. De imediato percebe-se uma das potencialidades destes ambientes: ao oferecer um sistema de representação semiótica que agrega a manipulação dinâmica aos objetos concreto-abstratos (a representação na tela do computador concretiza um objeto geométrico que é abstrato), ele desencadeia algumas das primeiras ações mentais características do raciocínio geométrico - o de estabelecer relações entre os objetos geométricos - e o faz de forma contundente, se comparado às possibilidades apresentadas no sistema de representação que faz uso do desenho estático em papel. (SOUZA e GRAVINA, 2009, p. 4).

Com isso, o aluno mantém o controle das etapas do fenômeno e do próprio ritmo de aprendizado. Além disso, incentiva a continuidade da busca pela compreensão do objeto de estudo, pois o próprio software auxilia na percepção visual e dinâmica das ações, que são manipuláveis com certo grau de permissividade.

O software Geogebra, projeto desenvolvido a partir de 2001 por Markus Hohenwarter na Universitat Salzburg, trata-se de um aplicativo de Matemática interativa e dinâmica que reúne conceitos de cálculo e álgebra. O GeoGebra é um software livre e escrito em linguagem Java, que tem o potencial para observação e manipulação de fenômenos. Pesquisas como as de Lopes (2013), Souza et al. (2010) e Maximiano et al. (2012) evidenciam que a utilização do software GeoGebra em ambientes de geometria dinâmica pode representar uma ferramenta importante na superação das dificuldades cognitivas dos alunos em processo de aprendizagem em sala de aula.

Assim, neste trabalho partimos do seguinte problema: como o conjunto de conceitos sobre o tema congruência entre triângulos retângulos evoluem durante o processo de ensino e aprendizagem a partir da utilização do software GeoGebra como instrumento pedagógico em uma Unidade de Ensino Potencialmente Significativa (UEPS)?

Nessa perspectiva, tivemos como objetivo analisar as respostas de alunos referentes a questionamentos aplicados durante o desenvolvimento de uma UEPS, a partir da utilização do software GeoGebra para a construção e análise de triângulos retângulos congruentes. 
Como aporte teórico utilizamos a Teoria da Aprendizagem Significativa de David Ausubel e como metodologia um estudo de caso de natureza qualitativa, que ocorreu durante dois encontros de duas horas/aula cada, em uma turma de 16 alunos participantes do projeto de extensão intitulado "Nivelamento" nos cursos de graduação em Física, Química e Matemática do campus Professor Alberto Carvalho da Universidade Federal de Sergipe, no ano de 2013, projeto que tinha por objetivo minimizar as deficiências de aprendizagem dos alunos calouros participantes nas disciplinas Física, Química e Matemática estudadas no nível médio da educação básica. Para preservar a identidade dos alunos, os mesmos foram nomeados por letras (A, B, C, ..., P). E para identificar evidencias de uma aprendizagem significativa a partir da utilização da UEPS, utilizamos como instrumento de coleta de dados os questionários e entrevistas respondidas pelos alunos ao decorrer da aplicação da unidade em sala de aula.

\section{A TEORIA DA APRENDIZAGEM SIGNIFICATIVA}

A aprendizagem significativa é uma teoria na qual a sua ideia central é a de que o fator isolado mais importante que influencia a aprendizagem é aquilo que o aluno já sabe. Isso significa que ela procura descrever, em linhas gerais, o que sucede quando o ser humano se situa e organiza seu mundo, preocupando-se com o processo de compreensão, transformação, armazenamento e uso da informação. Para Ausubel,

\footnotetext{
Se eu tivesse que reduzir toda a psicologia educacional a um único princípio, diria isto: o fator singular mais importante que influencia a aprendizagem é aquilo que o aprendiz já conhece. Descubra o que ele sabe e baseie-se nisso os seus ensinamentos. (AUSUBEL et al, 1980, p. 20).
}

Na visão de Ausubel (2003), a estrutura cognitiva de cada sujeito evidencia uma organização hierárquica e lógica, na qual cada conceito ocupa um lugar determinado em função de seu nível de abstração, de generalização e capacidade de incluir outros conceitos. Desta maneira, a aprendizagem significativa produz ao mesmo tempo a estruturação do conhecimento prévio e a extensão de sua potencialidade explicativa e operativa. Para Ausubel,

\footnotetext{
A aprendizagem significativa como processo pressupõe, por sua vez, que os aprendizes empreguem quer um mecanismo de aprendizagem significativa, quer que o material que apreendem seja potencialmente significativo para os mesmos, ou seja, passível de se relacionar com as ideias relevantes ancoradas nas estruturas cognitivas dos mesmos. (AUSUBEL, 2003, p.56).
}

Para Ausubel (2003, p.58), a eficiência da aprendizagem em sala de aula depende da capacidade de construção de relação não arbitrária e não literal entre ideias 
relevantes na estrutura cognitiva do aprendiz e conhecimentos novos a serem aprendidos e a capacidade de relação com a estrutura cognitiva particular de um aprendiz em particular - é mais propriamente uma característica do aprendiz do que o material em si.

Sendo isto posto, Novak vem expor três requisitos necessários para ocorrer a aprendizagem significativa:

(1). Conhecimentos anteriores relevantes: ou seja, o formando deve saber algumas informações que se relacionem com as novas, a serem apreendidas de forma não trivial. (2). Material significativo: ou seja, os conhecimentos a serem apreendidos devem ser relevantes para outros conhecimentos e devem conter conceitos e proposições significativos. (3). O formando deve escolher aprender significativamente. Ou seja, o formando deve escolher, consciente e intencionalmente, relacionar os novos conhecimentos com outros que já conhece de forma não trivial. (NOVAK, 2000, p. 19).

Assim, para que uma aprendizagem tenha o potencial de ser eficaz, segundo Valadares, ela deve ser significativa, o que exige que seja vista como a compreensão de significados. Para tal, segundo o autor, os conhecimentos a aprender necessitam ser relacionados com experiências anteriores e vivências pessoais dos alunos, permitindo a formulação de problemas de algum modo desafiantes e que incentivem o aprender mais. O estabelecimento de diferentes tipos de relações entre fatos, objetos, acontecimentos, noções e conceitos, desencadeando modificações de comportamentos, contribui para a utilização do que é aprendido em diferentes situações (VALADARES e FONSECA, 2007, p. 78).

Dessa forma, a aprendizagem significativa está relacionada à possibilidade dos alunos aprenderem por múltiplos caminhos e formas de inteligência; ou seja, com o uso de diversos meios, modos de expressão e tecnologias. Por isso, a aprendizagem significativa precisa ser assumida como um processo dinâmico, que exige ações de ensino direcionadas, para que os alunos aprofundem e ampliem os significados elaborados mediante as suas participações nas atividades de ensino e aprendizagem.

Assim, a Unidade de Ensino Potencialmente Significativa, termo utilizado por Moreira (2011) para denominar uma sequência didática adequada para a implementação dos princípios teóricos da Teoria da Aprendizagem Significativa, pode ser tornar uma circunstância que defina fundamentalmente característica e a natureza do material de ensino, que, para Moreira (2011, p. 25), não existe livro significativo, nem aula significativa, nem problema significativo, já que o significado está nas pessoas e não no material. 
Dessa forma, acreditamos que os softwares educativos, em nosso caso, o GeoGebra, pode representar um material potencialmente significativo no processo de aprendizagem, desde que apresente coerência na estrutura interna do material, sequência lógica nos conteúdos e que eles sejam compreensíveis para o sujeito que aprende, podendo ser enriquecido e modificado sucessivamente com conceitos em cada nova incorporação, interagindo de forma substantiva e não arbitrária os novos conhecimentos com o conhecimento prévio existente na estrutura cognitiva do aluno

\section{PASSOS PARA A CONSTRUÇÃO DE UMA UNIDADE DE ENSINO POTENCIALMENTE SIGNIFICATIVA (UEPS)}

A aprendizagem significativa evidencia-se por um processo de interação entre conhecimentos prévios relevantes da estrutura cognitiva do aluno e os novos conhecimentos, em busca de um novo significado. Essa interação se faz de forma não arbitrária e não literal. Na forma não arbitrária o próprio material relaciona as ideias relevantes da estrutura cognitiva do aluno. Portanto, os novos conhecimentos são uma consequência da interação ativa que ocorre entre o material de instrução e as ideias relevantes da estrutura cognitiva do aluno. Para Ausubel (2003) isso ocorrerá quando forem respeitadas duas condições: a existência de uma situação de aprendizagem significativa no aprendiz, o qual deve estar disposto a aprender, e de materiais de aprendizagem potencialmente significativos.

Buscamos, então, elementos que possam nos guiar a um material de ensino que seja potencialmente significativo à estrutura cognitiva do aluno, ancorados nos conhecimentos prévios relevantes existentes em tal estrutura, de forma que o aluno passe a ter um sistema de ideias ou conhecimentos organizados e significativos. Por isso, a elaboração da UEPS, segundo Moreira (2011(b), p. 45-46), deve considerar alguns passos:

Passo 01: definir o tema a ser trabalhado na UEPS, identificando aspectos procedimentais, tais como os aceitos no contexto da disciplina;

Passo 02: criar e/ou propor situações que possam oportunizar a identificação dos conhecimentos prévios relevantes da estrutura cognitiva dos alunos, tópico importante para obtenção de uma aprendizagem significativa; 
Passo 03: levando-se em conta o conhecimento prévio relevante identificado anteriormente, propor situações-problema que tenham o potencial de preparar o terreno para a introdução do material de ensino sobre o tema escolhido;

Passo 04: apresentar o conhecimento a ser ensinado/aprendido, levando em consideração a diferenciação progressiva;

Passo 05: retomar aspectos mais gerais sobre o tema, de forma a propor o conhecimento em um maior nível de complexidade, colocando novos exemplos e destacando semelhanças e diferenças em relação à primeira apresentação;

Passo 06: concluir a unidade retomando as características mais relevantes do conteúdo em questão buscando a reconciliação integrativa;

Passo 07: por último, realizar a avaliação da aprendizagem através da UEPS.

Segundo Moreira (2011(b), p. 46), a UEPS será considerada eficiente quando, durante a avaliação de desempenho dos alunos, proporcionar uma aprendizagem significativa, caracterizada por elementos como: melhor captação de significados, compreensão de conceitos, melhor capacidade de explicação, relacionar conceitos, aplicar o conhecimento adquirido para resolver situações-problema.

\section{A UTILIZAÇÃO DO SOFTWARE GEOGEBRA NA UEPS - RESULTADOS E ANÁLISES}

Ao se trabalhar com Geometria durante as aulas de matemática nos habituamos com objetos geométricos estáticos, algumas vezes manipulados com dificuldades utilizando o compasso e a régua no quadro negro, justificando os obstáculos encontrados em expressar para os alunos as generalidades dos teoremas, propriedades ou até fenômenos ocasionados com aqueles elementos.

Ao se utilizar o GeoGebra, nos encontramos com o mundo já conhecido dos softwares, mas ainda pouco explorado, que poderia nos fornecer um leque muito interessante de práticas educativas.

O que observamos em nossa prática docente é que muitos dos que já concluíram o ensino médio têm dificuldades na concepção de conceitos geométricos e na generalidade dos objetos geométricos e teoremas (TORRACA et al., 2013). Por isso, ao se utilizar o software GeoGebra pretendemos que ele tenha um potencial concernente à construção de conceitos em geometria, com 
[...] construtos individuais, até então deformados por imagens prototípicas, são reconstruídos através do "desenho em movimento", colocando em sintonia os significados individuais e os significados inseridos na geometria enquanto teoria matemática, e os alunos sentem-se mais motivados a buscar explicações para conjeturas formuladas em função de suas manipulações sobre os objetos geométricos dinâmicos e das evidências que daí emergem. (JIANG \& MCCLINTOCK, 1997; KEYTON, 1997, apud SOUZA E GRAVINA, 2009, p. 4).

Por isso, acreditamos que a utilização de estratégias como o software GeoGebra pode tornar as aulas mais dinâmicas, o que implica numa participação ativa do aluno e, de fato, auxiliar na promoção de um ensino centralizado no educando, o que é fundamental para facilitar a aprendizagem significativa. Com isso, espera-se um favorecimento do ambiente de aprendizagem, por agregar valor ao processo de ensino e possibilitar uma maior predisposição do aluno para aprender.

Como primeiro passo, a UEPS utilizando o software GeoGebra, teve como tema escolhido a congruência entre triângulos retângulos. Para isso, tivemos como aspectos procedimentais a construção, pelos alunos, de figuras geométricas e a identificação dos elementos geométricos explícitos expostos na construção e as propriedades geométricas implícitas, que não foram declaradas, mas que são evidenciadas com a geometria dinâmica a partir da figura geométrica construída, que no caso foram triângulos retângulos.

Inicialmente, foi realizada uma apresentação breve sobre o funcionamento do software GeoGebra, basicamente um tutorial de como realizar download, quais os requisitos técnicos mínimos para o computador, como executá-lo e como operacionalizar a utilização de determinadas variáveis da geometria, da álgebra e de equações matemáticas, além da construção e interpretação de gráficos do software.

No primeiro momento de aplicação da UEPS, desenvolvemos uma situação inicial que teve por finalidade identificar os conhecimentos prévios relevantes dos alunos e conhecer melhor o software, para isso realizamos a atividade intitulada: construção de um triângulo retângulo, na qual pretendíamos familiarizar os alunos com os ícones e variáveis do GeoGebra e, ao mesmo tempo, oportunizar aos mesmos conhecer os elementos que caracterizam um triângulo retângulo.

Com a tela do software GeoGebra aberta, solicitamos aos alunos que acionassem o ícone polígono e construíssem um triângulo retângulo. Em seguida, com ícone ângulo do software, encontrasse o valor dos três ângulos internos do triângulo formado. Com os triângulos devidamente construídos, realizamos as seguintes 
perguntas sem o auxílio de nenhum tipo de fonte bibliográficas, apenas com o auxílio do software: (1) o que caracteriza um triângulo retângulo? (2) denomine os lados do triângulo, indicando que são os catetos e a hipotenusa? (3) o que caracteriza a congruência entre dois triângulos retângulos?

No Quadro 01 encontram-se as respostas dos alunos para a primeira questão.

Quadro 01 - Identificação dos conhecimentos prévios dos alunos sobre triângulo retângulo.

\begin{tabular}{|c|l|}
\hline Aluno & \multicolumn{1}{|c|}{$\begin{array}{c}\text { Transcrição da resposta frente à questão: O que caracteriza um triângulo } \\
\text { retângulo }\end{array}$} \\
\hline A & Possui um dos seus ângulos reto. \\
\hline B & Tem duas retas que formam um ângulo de 90 graus. \\
\hline C & Único triângulo que possui ângulo reto. \\
\hline D & $\begin{array}{l}\text { Possui um dos seus ângulos reto, possui três lados dentre eles hipotenusa e dois } \\
\text { catetos, a hipotenusa fica do lado oposto do ângulo reto. }\end{array}$ \\
\hline E & Tem um ângulo de $90^{\circ}$. \\
\hline F & $\begin{array}{l}\text { Apresenta ângulo de } 90^{\circ} \text {, cujo a soma dos catetos opostos ao quadrado é igual a } \\
\text { hipotenusa ao quadrado. }\end{array}$ \\
\hline G & É um tipo de polígono. \\
\hline H & Ângulo de $90^{\circ}$ \\
\hline I & $\begin{array}{l}\text { Possui um ângulo reto e é formado a partir de três pontos, tendo como ângulos } \\
90^{\circ}, 35^{\circ} \text { e } 55^{\circ}\end{array}$ \\
\hline J & Figura geométrica com três lados, três ângulos, sendo que um deles vale $90^{\circ}$. \\
\hline K & Possui um ângulo de $90^{\circ}$ \\
\hline L & Tem um ângulo de $90^{\circ}$. \\
\hline M & Tem um ângulo de $90^{\circ}$ \\
\hline N & $\begin{array}{l}\text { Tem duas retas que forma um ângulo de } 90 \text { graus, dois ângulos de } 45 \text { graus e } \\
\text { obedece ao Teorema de Pitágoras }\end{array}$ \\
\hline O & Tem um ângulo de $90^{\circ}$. \\
\hline P & Contém três lados denominados hipotenusa, cateto oposto e adjacente. \\
\hline
\end{tabular}

Com relação a primeira questão, na qual tivemos por objetivo identificar os conhecimentos prévios dos alunos acerca do que caracteriza um triângulo como retângulo, observamos quatorze alunos que citaram um triângulo composto por um ângulo reto e alguns destes expuseram outras características. Como se trata de alunos que já concluíram o ensino médio, podemos notar subsunçores oriundos do processo de ensino e aprendizagem escolar, notados pela linguagem utilizada pelos participantes da pesquisa. Para Ausubel (2003), isso será preponderante para caracterizar as variáveis da estrutura cognitiva do aluno, oportunizando discutir sobre os conhecimentos que eles têm e se são relevantes, abrangentes, disponíveis e claros.

$\mathrm{Na}$ segunda questão, na qual tivemos por objetivo evidenciar se os alunos conseguiam identificar os lados do triângulo retângulo, podemos observar que todos os participantes conseguiram, levando-nos a acreditar que, nesse quesito, os alunos já 
possuem subsunçores adequados que poderão ser mobilizados para permitir a assimilação de novos conhecimentos durante todo o processo de ensino e aprendizagem.

$\mathrm{Na}$ terceira questão tivemos por objetivo identificar conhecimentos prévios sobre a congruência entre dois triângulos retângulos. Verificamos que dois alunos responderam citando: a congruência existe por conta da igualdade entre os lados e os ângulos (aluno D e G), já os outros quatorze alunos nada responderam. Com isto evidenciamos a possível dificuldade conceitual presente no tema.

A partir da identificação de alguns conhecimentos prévios relevantes e dificuldades na estrutura cognitiva do aluno sobre o tema, o professor iniciou a próxima atividade utilizando o próprio software GeoGebra como um organizador prévio, ou seja, uma ferramenta que didaticamente pode ter o potencial de auxiliar a aprendizagem significativa, na busca de situações desafiadoras que permita o aluno refletir sobre o conhecimento prévio ainda não identificado e o novo conhecimento a ser aprendido.

$\mathrm{Na}$ aprendizagem significativa, para se preencher a lacuna entre o conhecimento prévio relevante na estrutura cognitiva do aluno e o novo conhecimento, Ausubel sugeriu o que chamou de organizadores prévios, na qual se oferece um pequeno segmento de instrução antes da maior unidade educativa, numa forma mais geral e abstrata do que o material da unidade maior (NOVAK, 2000, p. 71). Essa instrução inicial que vem por intermédio do organizador prévio auxiliará ao aluno a gerar relações do conhecimento prévio com os novos conhecimentos a partir da estratégia de ensino.

Levando-se em consideração o conhecimento prévio relevante identificado anteriormente, foi proposto uma atividade que teve por objetivo preparar o terreno para a introdução do material de ensino sobre a congruência entre triângulos retângulos. Nessa atividade os alunos partiam da seguinte situação: utilizando o triângulo retângulo previamente construído na atividade anterior, os alunos traçaram uma reta perpendicular que passasse pela hipotenusa e pelo vértice oposto a ela e em seguida determinasse o ponto de intersecção entre a reta construída e o lado que ela está perpendicular, conseguido assim construir dois novos polígonos. Com o auxílio das variáveis fornecidas pelo Geogebra, os alunos poderiam visualizar os valores numéricos dos lados e dos ângulos dos triângulos construídos, oportunizando aos mesmos observar características que tornam os triângulos congruentes. 
Para observamos a evolução conceitual dos alunos a partir da realização da situação-problema da UEPS, realizamos um questionário composto por duas perguntas. A primeira foi: como você pode determinar se os dois triângulos são congruentes ou não? Esse questionamento tinha por objetivo identificar quais características tornam os triângulos congruentes. As respostas dos alunos encontram-se no quadro 02:

Quadro 02 - Respostas dos alunos referente a pergunta: como você pode determinar se os dois triângulos são congruentes ou não?

\begin{tabular}{|c|l|}
\hline Aluno & \multicolumn{1}{|c|}{ Transcrição das respostas } \\
\hline A & Os triângulos são iguais. \\
\hline B & Porque os dois triângulos têm ângulos iguais. \\
\hline C & Os dois apresentam ângulos iguais. \\
\hline D & Os triângulos são iguais. \\
\hline E & Os triângulos são iguais. \\
\hline F & Formado por duas retas iguais usando o ponto D para separar os triângulos \\
\hline G & Através dos valores dos ângulos. \\
\hline H & Tem o mesmo ponto de intersecção e mesmo ângulos internos. \\
\hline I & Os dois apresentam ângulos iguais. \\
\hline J & Os valores de seus ângulos internos são iguais. \\
\hline K & Relação de proporcionalidade entre os lados do triângulo. \\
\hline L & Tem os mesmos ângulos internos. \\
\hline M & Ângulos opostos com valores iguais \\
\hline N & Porque os dois triângulos têm ângulos iguais. \\
\hline O & Tem os mesmos ângulos internos. \\
\hline P & Lados de mesmo tamanho. \\
\hline
\end{tabular}

Nessa questão, observamos durante a construção da atividade, que todos alunos conseguiram enxergar na construção dos triângulos que eles eram congruentes. Nas respostas à questão identificamos que dez alunos citaram que a congruência era devido a igualdade dos valores dos ângulos dos triângulos formados, três citaram que era devido a igualdade dos lados e três citaram que os triângulos eram iguais.

A segunda pergunta foi: Ao clicar no ícone ângulo você poderá colocar os valores dos ângulos dos dois triângulos, a que conclusão você pode chegar com os valores encontrados? O objetivo desse questionamento foi impelir que os alunos recorressem aos ângulos correspondentes para atestar a congruência entre os triângulos. Das respostas podemos observar novamente que todos os alunos chegaram à conclusão durante a execução da atividade que os dois triângulos são congruentes e agora treze deles justificaram que isso ocorria por conta da igualdade entre os ângulos internos.

Notadamente, a utilização de uma estratégia não familiar conferiu ao material uma ação didática que teve de ser mediada pelo professor, pois só assim foi possível 
refletir acerca das diferenças que existem entre o conhecimento antigo e o novo conhecimento, entre uma matemática estática fundamentada nos teoremas memorizáveis e uma matemática na qual os alunos tiveram a oportunidade de chegar as suas próprias conclusões acerca do tema. Para Ausubel (2003), quer na aprendizagem por memorização, quer na significativa, a aplicação do material de ensino pode ser afetada por fatores como tendências culturais e de atitude e pelas exigências de situações específicas do próprio âmbito da aplicação, isso significa que a não familiaridade com a ferramenta pode significar um obstáculo ao processo de aprendizagem, porém isso também demonstra a superioridade da aprendizagem e retenção se significados a partir de uma aprendizagem que seja significativa.

Nesse momento da UEPS, apresentamos o conhecimento a ser ensinado/aprendido. Com o auxílio do software GeoGebra e um projetor multimídia, o professor discutiu os conceitos essenciais para a aprendizagem do tema congruência entre triângulos retângulos. Nessa situação podemos observar que o aluno passa a ter um comportamento diferente em relação ao processo de ensino e aprendizagem, pois tornou-se mais participativo nas discussões e no desenvolvimento de estratégias que tem o potencial de aperfeiçoar a aprendizagem.

Após apresentação do conhecimento a ser ensinado/aprendido, passamos a um novo momento da UEPS que foi retomar aspectos mais gerais sobre o tema, de forma a propor o conhecimento em um maior nível de complexidade, colocando uma nova situação de ensino. Para Ausubel (2003), no processo de ensino e aprendizagem são necessários materiais instrutivos dependentes de uma sequência que seja evolutivamente complexa. Nesse momento foi proposto uma atividade na qual tivemos por objetivo a verificação da congruência entre triângulos a partir da identificação da proporcionalidade existente entre os lados dos triângulos retângulo.

Para isso sugerimos a seguinte situação: inserimos um ponto, que o GeoGebra chama de ponto-objeto, em seguimentos correspondentes dos dois triângulos retângulos construídos na parte anterior. Em seguida, também utilizando o recurso do software, incluímos a ação animar a esses pontos-objeto, fazendo com que eles se movimentassem pelos triângulos, percorrendo os segmentos correspondentes dos triângulos no mesmo intervalo de tempo. Dessa forma, os alunos poderiam observar a existência de proporcionalidade entre os lados do triângulo, concluindo que os triângulos são congruentes. A partir dessa situação pretendemos identificar se os alunos 
conseguiram observar a congruência dos triângulo, para isso utilizamos o seguinte questionamento: o que você pode concluir em relação aos deslocamentos dos pontoobjeto observados nos triângulos? As respostas encontram-se no quadro 03.

Quadro 03 - Respostas dos alunos referente a pergunta: o que você pode concluir em relação aos deslocamentos dos ponto-objeto observados nos triângulos?

\begin{tabular}{|c|l|}
\hline Aluno & \multicolumn{1}{c|}{ Transcrição das respostas } \\
\hline A & Os pontos percorrem os triângulos ao mesmo tempo. \\
\hline B & Os pontos vão se encontrar em um determinado local \\
\hline C & $\begin{array}{l}\text { Que embora tenham deslocamentos diferentes, sempre chegam ao mesmo ponto de } \\
\text { partida, isso prova que são congruentes. }\end{array}$ \\
\hline D & $\begin{array}{l}\text { No ponto E os pontos sempre se encontram, e percorrem os triângulos ao mesmo } \\
\text { tempo. }\end{array}$ \\
\hline E & Não respondeu. \\
\hline F & Que os pontos se deslocam ao mesmo tempo em torno do seu próprio triângulo. \\
\hline G & Os pontos se encontram. \\
\hline H & Eles se encontram em um ponto \\
\hline I & $\begin{array}{l}\text { Que mesmo tendo deslocamentos diferentes, sempre chegam ao mesmo ponto, isso } \\
\text { prova que são congruentes. }\end{array}$ \\
\hline J & Que os pontos sempre vão se encontrar. \\
\hline $\mathrm{K}$ & Tempo percorrido em catetos congruentes é igual. \\
\hline $\mathrm{L}$ & Os pontos se encontram. \\
\hline $\mathrm{M}$ & Encontro entre os pontos. \\
\hline $\mathrm{N}$ & Os pontos vão se encontrar em determinado local. \\
\hline $\mathrm{O}$ & Os pontos se encontram. \\
\hline $\mathrm{P}$ & Os pontos se encontram. \\
\hline
\end{tabular}

A partir da coleta dos dados identificamos que apenas três alunos evidenciaram que os pontos-objeto percorrem diferentes espaços no mesmo intervalo de tempo por conta dos lados que são proporcionais, caracterizando assim triângulos retângulos congruentes.

O aumento do nível de complexidade na atividade, partindo para uma situação não familiar para os alunos coloca em discussão o próprio processo de formação dos mesmos, uma vez que se trata de alunos que já concluíram o ensino médio. Nota-se que o desenvolvimento da aprendizagem nos anos de educação básica pode ter influenciado no desenvolvimento cognitivo de forma crucial, diminuindo a eficácia de qualquer processo de aprendizagem que não esteja alicerçado na memorização. Para Ausubel (2003), o adiamento da experiência de um ensino significativo desperdiça oportunidades de aprendizagem valiosas e, muitas vezes, reduzindo, de forma desnecessária, a quantidade e complexidade do conteúdo. 
Após discussões sobre o tema em sala de aula, podemos observar também que os alunos tinham uma parcela do conhecimento matemático associado à Física, mais especificamente a razão entre o espaço percorrido e o intervalo de tempo, que seria uma constante, chamada na Física de velocidade média, por isso eles conseguiram identificar que os pontos-objeto percorrem lados diferentes ao mesmo tempo, porém apenas três identificaram a existência de uma proporcionalidade nas dimensões dos lados, o que caracterizava também os triângulos como congruentes. Essa situação oportunizou uma discussão mais aprofundada sobre o tema, retomando as características mais relevantes do conteúdo com o auxílio do professor.

Para a conclusão da UEPS, retomamos as características mais relevantes do conteúdo e buscamos discutir possíveis lacunas conceituais.

Sabendo que a aprendizagem significativa é progressiva e procurando identificar potencialidades do material de ensino, realizamos uma entrevista com os alunos participantes como um ato de avaliação da aprendizagem através da UEPS. Das concepções dos alunos podemos destacar:

Aluno C: A utilização do software GeoGebra facilitou a aprendizagem do conteúdo.

Aluno D: Acho que as atividades desenvolvidas ficaram bem claras, auxiliou no entendimento do conteúdo sem a necessidade de decorar fórmulas.

Aluno M: O material possibilitou aprender um assunto ao qual poucos tem facilidade, mesmo assim percebemos que os triângulos são semelhantes através do Geogebra.

Enfim, acerca da UEPS, notamos a partir das concepções dos alunos, que a experiência de aprendizagem na aprendizagem significativa foi agradável e satisfatória, possibilitando aguçar a curiosidade intelectual e a perspectiva de se adquirir novos conhecimentos.

\section{CONCLUSÕES}

Apesar de ser extremamente difícil analisar os registros e encontrar padrões ou regularidades que nos forneçam indícios que o material é potencialmente significativo, a partir da coleta de dados podemos concluir que a utilização do software GeoGebra pode se tornar uma ferramenta importante no processo de aprendizagem dos alunos. Observamos indícios que a utilização do software foi potencialmente significativa, pois 
se tratou de uma sequência didática que teve como maior potencial a facilitação da aprendizagem significativa e a participação ativa do aluno.

Essa UEPS oportunizou uma construção inicial da capacidade que o aluno individualmente demonstra para a utilização do conhecimento prévio em relação ao novo conhecimento a ser adquirido, de forma contrária à aprendizagem por memorização, desenvolvendo a evolução do conhecimento de maneira mais estável através da inserção interativa e dinâmica de elementos sobre o tema que diferem do "formulismo" que encontramos nas aulas de Matemática.

A investigação desenvolvida a partir da utilização do software GeoGebra como ferramenta pedagógica na construção de Unidades de Ensino Potencialmente Significativas também se justificou pelo fato de observarmos as condições de aprendizagem aplicadas em sala de aula que podem proporcionar modificações no processo de ensino e de aprendizagem. Isso oportuniza a aplicação direta e sistemática desse software em um período de tempo mais longo. Podendo tornar o processo de ensino mais predisposto a ser motivador e potencialmente significativo para a concepção de novos currículos e novas formas de ensino e de aprendizagem.

\section{REFERÊNCIAS}

AUSUBEL, D. P., NOVAK, J. D. e HANNESIAN, H. (1980). Psicologia educacional. Rio de Janeiro. Interamericana.

AUSUBEL, David. P. Aquisição e retenção de conhecimentos: uma perspectiva cognitiva. Plátano edições técnicas, 2003, Lisboa/Portugal.

BRASIL, Lei de Diretrizes e B. Lei no 9.394/96, de 20 de dezembro de 1996.

BRUM, Wanderley Pivatto e SILVA, Sani de Carvalho Rutz da. A utilização de uma UEPS no ensino de matemática: uma investigação durante a apresentação do tema probabilidade. Aprendizagem Significativa em Revista - V5(1), pp. 15-32, 2015.

LABORDE, Colette. Robust and soft constructions: two sides of the use of dynamics geometry environments. In Proceedings of the Tenth Asian Technology Conference in Mathematics (2005), 22-35. Korea National University of Education, Cheong-Ju, South Korea.

LOPES, Maria Maroni. Sequência didática para o ensino de trigonometria usando o software GeoGebra. Revista Bolema, Rio Claro, v. 27, n. 46, p. 631-644, agosto de 2013. 
MAXIMIANO, Rosemeiry de Castro Preado; SILVEIRA, Marcelo; BELLOTI, Eunice Corrêa Sanchis; ROSSINI, Marcela Penteado; BACILLI, Valéria Cristina Leite; ORLANDI, André Luis. O GeoGebra e o ensino da Física: aprender a aprender. In Atas da conferência latino-americana de GeoGebra, 2012, Uruguai, p. 365-372.

MORAES, Roque e GALIAZZI, Maria do Carmo. Análise textual discursiva. Editora Unijuí, Ijuí, 2011.

MOREIRA, Marco Antônio. Unidades de Enseñanza Potencialmente Significativas UEPS. Aprendizagem Significativa em Revista/Meaningful Learning Review - V1(2), pp. 43-63, 2011.

NOVAK, Joseph D. Aprender, criar e utilizar o conhecimento. Plátano edições técnicas, Lisboa, 2000.

SOUZA, Carlos Eduardo; GRAVINA, Maria Alice. Geometria com animações interativas. CINTED/UFRGS - Novas Tecnologias da Educação, vol. 07 n. 01, Julho, 2009.

RIBEIRO, Tiago Nery. A utilização de software de geometria dinâmica como ferramenta pedagógica nas aulas experimentais de matemática. Anais do $\mathrm{V}$ Colóquio internacional "Educação e contemporaneidade". ISSN 1982-3657. Realizado no período de 21 a 23 de Setembro de 2011 em São Cristóvão, SE.

SOUZA, Aguinaldo Robinson; ARÉVALO, Diego F. Vizcaíno; VIVEIROS, Edval Rodrigues; ABRIL, Olga L. Castiblanco. Uso de GeoGebra para analisar o movimento harmônico simples por meio do pêndulo simples. In.: PIROLA, N. A.(org). Ensino de Ciências e Matemática IV: temas de investigação (on line). São Paulo. Editora Unesp, São Paulo, cultura acadêmica, p. 175-204, 2010.

TORRACA, Marcelo; ALVES, Geneci; DIAS, Priscila; NASSER, Lilian. Preparando para a aprendizagem de cálculo: funções e geometria no ensino médio. In Flores, Rebeca (Ed.), Acta Latinoamericana de Matemática Educativa, México, DF: Comité Latinoamericano de Matemática Educativa. p. 1741-1749. 2013.

VALADARES, Jorge; FONSECA, Fédora. Uma estratégia construtivista e investigativa para o ensino da óptica. 2007, Revista ABRAPEC, v.4 n.3, p. 74 a 85.

VIANA, Odalea Aparecida; BOIAGO, Carlos Eduardo. Registros de representação semiótica em atividades de desenho geométrico no GeoGebra. Revista Eletrônica de Educação Matemática, v. 10, n. 1, p. 162-182, 2015. 